\title{
The Effect of Ethical Leadership on Organizational Learning: Evidence from a Petroleum Company
}

\author{
Muhammad Usman $^{1}$, Ahmed Abdul Hameed ${ }^{2}$
}

\begin{abstract}
The purpose of the study was to explore the effect of two aspects - accountability and fairness - of ethical leadership on organizational learning, understood in broader sense as constructive and destructive learning. Case study was used as research methodology and data was collected using 35 semi-structured interviews from the employees and managers of the case study company. Data was analyzed using open, axial and selective coding. The findings suggest that accountability discourages employees from learning destructive practices. Moreover, accountability enhances constructive learning. The findings also show that the lack of fairness and accountability amongst organizational leadership creates a culture that facilitates the penetration and propagation of destructive practices in organizations. The literature has highlighted but not explored the influence of ethical leadership on organizational learning. The study is the first to empirically explore the links between these two important constructs. This study suggests that organizational leaders can enhance constructive learning and deter destructive learning by demonstrating fairness and accountability through their behaviors and actions.
\end{abstract}

Keywords: Ethical leadership, accountability, fairness, constructive learning, destructive learning

\section{Introduction}

The business world has witnessed a number of high profile failure scandals such as Parmalat, Worldcom, Enron and Allied Irish Bank. It is argued that lack of ethics and ethical leadership has contributed to such failure scandals (Brown \& Treviño, 2006; Eisenbeiß \& Brodbeck, 2014; Knights \& O'Leary, 2005; Martin, Keating, Dickson, Kwan \& Peng, 2011; Xu, Loi \& Ngo, 2016). The importance of ethical behavior of the leaders has been acknowledged for the improved performance and growth of

1 Assistant Professor, COMSATS Institute of Information Technology 1.5 KM Defence Road, off Raiwind Road, Lahore, Pakistan. Phone: +92 (42) 111001007, Email: hmusman10@yahoo.com 2 Ahmed Abdul Hameed, Ph.D. Scholar, COMSATS Institute of Information Technology 1.5 KM Defence Road, off Raiwind Road, Lahore, Pakistan. Phone: +92 (42) 111001007, Email: ahmed_abdul_hameed@yahoo.com

\begin{tabular}{|c|c|c|}
\hline ARTICLE HISTORY & & \\
\hline $21 \mathrm{Jul}, 2017$ Submission Received & 29 Aug, 2017 & First Review \\
\hline 19 Sep, 2017 Revised Version Received & 15 Oct, 2017 & Second Review \\
\hline 1 Nov, 2017 Revised Version Received & 15 Nov, 2017 & Accepted \\
\hline
\end{tabular}


a range of different organizations and institutions such as business organizations, sports teams and religious institutions (Brown \& Treviño, 2006; Treviño, Weaver \& Reynolds, 2006; Tseng \& Wu, 2017).

The literature also acknowledges the need for further attention on ethics and ethical leadership for the improvement in organizational practices and performance (Brown, Treviño \& Harrison, 2005; Brown \& Treviño, 2006; Eisenbeiß \& Brodbeck, 2014; Engelbrecht, Heine \& Mahembe, 2017; Kalshoven, Den Hartog \& De Hoogh, 2011; Liu, Kwan, Fu \& Mao, 2013; Price, 2000; Tseng \& Wu, 2017). We understand ethical leadership as "the demonstration of normatively appropriate conduct through personal actions and interpersonal relationships, and the promotion of such conduct to followers" (Brown et al., 2005, p. 120). Brown et al. (2005) suggest that an ethical leader sets example of the ethical behavior and practices for the employees and focuses on developing mechanisms that discourage the propagation of unethical practices in organizations. This suggests that ethical leadership can play important role not only in impeding unethical and destructive organizational practices from penetrating the organizations, but it can also help the organizations learn constructive practices.

Following Brown et al. (2005), we mainly draw on social learning theory (Bandura, 1977 ; 1986) to suggest the role of ethical leadership in discouraging the penetration of destructive practices in organization and enhancing constructive organizational learning important. Social learning theory posits that individuals learn appropriate behaviors through a role-modeling process, by observing the behaviors of others. Employees are likely to emulate the practices and behaviors of their managers as their leaders and role models. Given their positions in organizations, organizational leaders can force and legitimate ethical behavior in organizations through their power to punish and reward. That is, ethical leaders may use both their normative power and the role-modeling role to discipline and reward ethical practices to deter unwanted practices and enhance learning of constructive practices.

Therefore, we propose that ethical leadership affects organizational learning, understood in this study in a broader sense as constructive learning - improvement in organizational practices (Mason \& Leek, 2008) and destructive learning - deterioration in organizational practices (Coopey \& Burgoyne, 2002). Although contemporary literature makes valuable contributions by bringing to the fore the importance of ethical leadership and organizational learning and unlearning for organizational growth and sustained competitive advantage, empirical literature on the links between ethical leadership and organizational learning is scarce. This study, using a single case of Alpha Petroleum (pseudo name of a company involved in the marketing and distribution of petroleum products in one of Indian sub-continent countries) investigates the effect of ethical leadership on organizational learning by generating insights into: 
1. How does ethical leadership play a role in discouraging destructive practices in organizations?

2. How does ethical leadership contribute in enhancing constructive organizational learning?

Our study contributes to two important areas of knowledge - ethical leadership and organizational learning - by showing links between ethical leadership and different aspects of organizational learning. Our study is particularly important, as the empirical studies on the links between ethical leadership and organizational learning are scarce. To our knowledge, our study is the first endeavor to study these links. Thus, our study is important, as it provides empirical evidence on the links between ethical leadership and organizational learning, understood in a broader sense as constructive and destructive learning. Our findings carry important implications for the policy makers and managers that can help organizations improve impede destructive learning and enhance constructive learning. This can ultimately lead to organizational success and help organizations gain competitive advantage.

This paper is organized in five sections. In section 2, literature on ethical leadership and organizational learning will be reviewed to develop a theoretical framework. In section 3, we will explain research method used in this study. Then we turn to present empirical results in section 4 . In section 5 and 6 , discussion and conclusion will be presented respectively.

\section{Theoretical Background}

\subsection{Organizational learning, constructive and destructive}

Organizational learning has gained much attention from the researchers during the past few decades. Organizational learning manifests in the improvement in organizational practices and processes and helps organizations achieve and sustain competitive advantage (Chiva \& Habib, 2015; Mason \& Leek, 2008). Organizational learning rejuvenates the competencies of the firms and make them flexible and dynamic to counter the effects of changing market dynamics (Fiol \& Lyles, 1985; Mason, Oshri \& Leek, 2012; Senge, 1990). Following the common constructive notion of organizational learning, we understand organizational learning as the capability that improves organizational practices and performance (Fiol \& Lyles, 1985; Senge, 1990; Mason et al., 2012).

However, organizations do not necessarily learn practices and behaviors that improves organizational practices and performance (Argyris \& Schön, 1996). Organizational members can engage in practices such as corruption, bribery, nepotism 
and the manipulation of organizational resources for personal gains that impede organizational performance (Aguilera \& Vadera, 2008; Rodriguez, Siegel, Hillman \& Eden, 2006). Similarly, organizational culture and structure may not be suitable for, and impede, organizational learning. For instance, bureaucratic and hierarchical structures are argued to hamper knowledge sharing and new knowledge creation (Coopey \& Burgoyne, 2000; Mason \& Leek, 2008). We argue that ethical leadership discourages the penetration of destructive behaviors and practices in organizations and enhances constructive organizational learning.

\subsection{Aspects of ethical leadership and organizational learning}

Literature suggests that leaders usually fail to follow and implement ethical standards in the organizations and this failure contribute to the failure of businesses (Hassan, Wright \& Yukl, 2014; Kacmar, Tillman, Harris, Whitman \& Justice, 2016). Given the globalized nature of businesses and societies, business failures in one country negatively affect the trust of the investors and customers in many countries around the world (Kacmar et al., 2016; Ofori, 2009). Therefore, the leadership of different organizations is under pressure to demonstrate ethical behavior and develop mechanisms that encourage ethical behavior among the followers for the purpose of improved and sustainable organizational performance (Kacmar et al., 2016; Price, 2000; Resick, Hanges, Dickson \& Mitchelson, 2006). Thus, it is important for organizational leaders to embrace behaviors and practices that are consistent with ethical standards and values of different cultures and societies in order to succeed in an era in which organizational and national boundaries are blurred (Jackson, 2001; Kacmar et al., 2016).

Ethical leaders are understood as fair, sincere, upright and honest (Brown \& Treviño, 2006). Ethical leaders demonstrate integrity and concern and care for others in their personal and professional lives (Brown \& Treviño, 2006; Brown et al., 2005). However, the ethical leadership concept has been criticized because of the substantial overlap it shares with other related leadership styles such as authentic and transformational leadership (Avolio \& Gardner, 2005; Bakari \& Hunjra, 2017; Walumbwa, Avolio, Gardner, Wernsing \& Peterson, 2008). Indeed, ethical leadership attributes such as fairness, trustworthiness, honesty, integrity and concern for others are also included in the ethical component in authentic leadership and transformational leadership (Avolio \& Gardner, 2005; Burns, 1978).

However, literature differentiates ethical leadership from other leadership styles mainly on the basis of two important features (Brown et al., 2005; Brown \& Terviño, 2006). First, the other leadership styles conceive ethics as one of the facets of leadership rather than the central facet of leadership (Brown et al., 2005). For instance, 
transformational leadership's main focus is on gaining the support of followers to achieve organizational objectives (Arnold, Turner, Barling, Kelloway \& McKee, 2007). Building on social learning theory (Bandura, 1977; 1986), Brown et al (2005) posit ethics as the sole and central tenant of ethical leadership instead of a peripheral component. Second, literature (Brown \& Treviño, 2006; Brown et al, 2005) identified two roles of an ethical leader - the ethical leader as a moral manager and the ethical leader as a role model. As a moral manager, the ethical leader is inclined more to use transactional approaches and tactics to discourage the penetration of unethical behaviors in organizations and encourage ethical behaviors. The transactional tactics may involve a transparent reward and punishment system. In other words, in this role, leaders use their normative power and authority to force ethical behavior in organizations. Importantly, ethical leaders endeavor to shape their followers' behavior by setting up and following ethical standards, communicating the standards to the followers and establishing fair accountability system (Brown \& Treviño, 2006; Tuckey, Bakker \& Dollard, 2012). Moreover, as role models, ethical leaders demonstrate ethical behavior, and social learning theory suggests that followers see their leaders as role models, observe their behaviors, learn from them and endeavor to imitate them. By categorizing ethical leadership in these roles, Brown et al. (2005) portray ethical behavior of leaders and followers equally important and a central aspect of organizational life. By doing so, Brown et al. (2005) highlight the imperative role of ethical leadership in encouraging and forcing ethical behavior in organizations through the role-modeling and normative roles, respectively.

As did Brown et al. (2005), we draw on social learning theory to suggest that ethical leaders use both normative and role-modeling roles to discourage destructive behavior and practices as well as enhance constructive learning.

\subsubsection{Fairness}

As already discussed, literature brings to the fore a number of different but closely related aspects of ethical leadership. Resick et al. (2011) suggest that honesty, integrity, trustworthiness, sincerity, authenticity, self-discipline and courage and good intentions are important aspects of ethical leadership. In this study, following Brown \& Treviño (2006) and Xu et al (2016), we focus on two aspects of ethical leadership - fairness and accountability - given the importance of these aspects for employee motivation, performance and productivity. Our choice of accountability is inspired by the argument that accountability is a key aspect that can overcome destructive practices and can contribute to economic and social development (Aguilera \& Adera, 2008). The argument that fairness is one of the key features of ethical leadership that positively influences behavior and performance outcomes of employees (Brown et al., 2005; Price, 2000) warrants our interest in fairness. 
Ethical leaders create a good working environment through fair decisions (Brown et al., 2005). Mayer, Kuenzi, Greenbaum, Bardes and Salvador (2009) suggest that employees usually respond to fair decisions in positive ways including improved performance and productivity that may go beyond the usual performance expectations. Moreover, the fairness of ethical leaders is not limited to within the organizational boundaries; rather, they make decisions that are fair for the customers and society at large (Piccolo, Greenbaum, Hartog \& Folger, 2010). Eisenbeiß and Brodbeck (2014) maintain that ethical leaders' decisions are equally fair to the followers, organizational employees, customers and other stakeholders including suppliers, politicians, society and trade unions. Ethical leaders treat society with respect, dignity, fairness and justice (Eisenbeiß \& Brodbeck, 2014). Therefore, following social learning theory and the concept of ethical leaders as role models, we suggest that followers would learn and imitate these behaviors of their leaders. According to Piccolo et al. (2010), fairness in dealing with organizational members promotes ethical practices in the organization and discourages unethical practices. Thus, we argue that ethical leadership can contribute to impede destructive practices such as unfair treatment of workers to penetrate the organizations. Similarly, if leaders are fair in rewarding employees and evaluation of performance, employees may strive hard for learning new skills and improve their practices, as fair and transparent reward management and performance appraisal systems motivate employees to acquire, share and use new knowledge (Riege, 2005; Bozionelos \& Wang, 2007).

\subsubsection{Accountability}

Accountability refers to personal accountability, following laws, rules and regulations and making others responsible and accountable for their actions (Resick et al., 2011). Ethical leaders portray and promote ethical behaviors and standards and develop different mechanisms to make people accountable for their actions (Brown \& Treviño, 2006; Treviño et al., 2006). Using their position in the organization and its associated normative powers, ethical leaders create an organizational structure that strengthens and supports ethical behavior and imposes penalties on those who violate ethical standards (Treviño et al., 2006). Literature (Brown \& Treviño, 2006; Resick et al., 2011; Treviño et al., 2006) suggests that accountability discourages destructive practices such as corruption, bribery and nepotism that impede organizational performance. Similarly, accountability ensures that organizational members follow rules and regulations and ethical standards while they strive for career growth, promotion and so on (Brown \& Treviño, 2006; Resick et al., 2011). Thus, we expect that ethical leaders can contribute to the improved skills and learning of employees and enhance constructive organizational learning. 


\section{Research Method}

\subsection{Research philosophy}

Creswell (2003) argues that the choice of research methodology must suit the purpose and nature of the research. Moreover, Morgan and Smircich (1980) suggest the selection of the research design of the study should commence with the choice of a suitable research philosophy. The failure to build assumptions regarding the nature of reality indicates that it is the inclination towards a particular research design that determined the nature and purpose of the research, instead of the nature and purpose of the study guiding the selection of an appropriate research design (Morgan \& Smircich, 1980).

As far as philosophical orientation is concerned, this study is based on practical constructivism (Kjellberg \& Helgesson, 2006). For ontological position, practical constructivism assumes that social reality is an on-going process of creation, and emphasizes the emergent, enacted character of reality instead of being concerned about the existence of social reality dependent or independent of our perceptions of it. Practical constructivism assumes that social realities are relational effects (Law \& Urry, 2004). Practical constructivism does not deny that social reality can be real (Law \& Urry, 2004, p. 396). However, practical constructivism emphasizes that there is “... no definite social reality that can be discovered" (Kjellberg \& Helgesson, 2006, p. 841). As far as the epistemological position is concerned, practical constructivism takes a position that social reality is constituted and shaped through continuous and extended interactions, associations and performative effects of different practices (Kjellberg \& Helgesson, 2006; Law, 1994; Law \& Urry, 2004). These practices are performed by a variety of actors with different versions and interpretations of social reality and logics of actions. The interactions and contestations between multiplicity of practices and entities as well as between theoretical influences shape and reshape social reality (Kjellberg \& Helgesson, 2006; Law, 1994; Law \& Urry, 2004). Consequently, practical constructivism assumes that multiple truths can be enacted depending on the purpose, interpretations, context and the way they are associated with, and affect, one another.

By placing an emphasis on emergent, enacted and performative nature of social reality, we argue that practical constructivism helps us understand how does ethical leadership play a role in discouraging destructive practices in organizations and contribute to the improvement in organizational practices? Importantly, by stressing the existence multiple truths, this approach directs attention towards different forms of destructive and constructive practices as well as explore and foreground the multiple effects of ethical leadership through its different facets (accountability and fairness) on organizational learning. Thus, practical constructivism suits the nature of our study. 


\subsection{Qualitative approach and case study as research methodology}

We adopted a qualitative approach in this study. Our choice of the qualitative approach to a single case study is informed by a number of reasons. First, surprisingly, there is little known, theoretically or empirically, about the links between ethical leadership and learning. Thus, the choice of a qualitative approach was natural to build theoretical knowledge (Yin, 1994). Second, the research questions of the study ("how does ethical leadership play a role in discouraging destructive practices in organizations? And how does ethical leadership contribute in enhancing constructive organizational learning?") also suggest the use of a qualitative approach. 'How' and 'why' questions are studied through a qualitative approach to help generate deep insights into the social phenomena (Creswell, 2003). Finally, qualitative research suits practical constructivism that stresses the emergent, enacted and performative nature of social reality (Kjellberg \& Helgesson, 2006). In essence, keeping in view the nature and purpose of this study as well as the research philosophy adopted, we used qualitative research approach.

Moreover, we adopted a single case study to answer our research questions. A single case study helps in-depth exploration of complex phenomena by focusing on how and why realities are formed in real life social settings and allows the examination of contextual realities (Bryman \& Bell, 2007; Yin, 1994). A single case study provides an opportunity to understand social reality from various perspectives, vantage points and dimensions and generates in-depth information about the phenomenon under study (Dubois \& Gadde, 2002). According to Dubois and Gadde (2002), a single case study provides unique means of generating theories through rich insights of the phenomenon and its context.

\subsection{Data collection}

A single case study of Alpha Petroleum has been used as research methodology. Using a single case of Alpha to explore the influence of ethical leadership on organizational learning is expected to produce in-depth insights (Eisenhardt, 1989) into the ethical leadership and organizational learning. Data collection in case studies usually involves semi-structured interviews, in-depth interviews, document analysis, observations and archival records analysis (Yin, 1994). We mainly relied on semi-structured interviews for data collection, as semi-structured interviews help generate deep insights into the understudy social phenomena (Graneheim \& Lundman, 2004). We also reviewed a number of documents such as minutes of meeting, memos and seminars' proceedings relevant to ethical leadership and organizational learning.

Access for data collection was managed through personal references. A total of 
35 interviews were conducted from employees and managers working in different departments of Alpha Petroleum. 20 interviews were conducted from employees and 15 from managers. A combination of purposive and convenience sampling was used to select the interviewees (Bryman \& Bell, 2007). The sampling technique was purposive, as we purposefully chose managers as well as employees working in different departments and different levels in the organization. The aim was to gain insights and understand multiple perspectives about ethical leadership, destructive practices and constructive learning and links among these constructs. The sampling technique was convenience sampling, as we interviewed employees and manager on the basis of our convenience to approach them and willing to participate in interview. Interviews were conducted from two zonal offices (chosen on the basis of our convenience) of Alpha Petroleum that are located in the capital cities of the two provinces of the country. The tenure of the interviewees with Alpha Petroleum ranged from 3 to 20 years. Interview durations ranged from 90 to 150 minutes. Interviews were conducted between March and May 2016.

Written consent was taken from all the interviewees. They were informed about the purpose of this study. They were ascertained that their identity would not be revealed. They were informed that they could skip any question and also leave the interview at any stage.

The interviewees were asked different questions relevant to learning and the aforementioned four aspects of ethical leadership. For instance, they are asked about different learning mechanisms such as the focus of leadership on the development of knowledge sharing practices, training and any rewards for learning new things. They were asked about the leadership's concern for employees' personal and professional matters and problems, honesty, fair and transparent promotion and career development opportunities for employees and accountability mechanisms. An initial set of semi-structured questions is presented in table (1). To prepare interview guide (table 1), we followed Brown et al. (2005) and Yukl, Mahsud, Hassan and Prussia (2013) for ethical leadership constructs and Argyris and Schön (1996), Senge (1990) and Mason et al. (2012) for organizational learning. These studies helped us extract key themes that were relevant to our research questions. Then we followed Kvale (2007) and Turner (2010) to phrase the questions to suit the purpose and analytical approach of our study.

\subsection{Data analysis}

Transcribed interview data was analyzed using open, axial and selective coding (Strauss \& Corbin, 1990). We used open coding with a specific goal to recognize the key features and dimensions of various perceptions and concepts that emerged from 
Table 1: Semi-structured Questions

\begin{tabular}{|c|c|}
\hline Construct & Questions \\
\hline Fairness & $\begin{array}{c}\text { Does your boss show favoritism to anyone? } \\
\text { Does your boss pursue his/her own success at the expense of others? } \\
\text { Does he exploit / manipulate subordinates? } \\
\text { Are his / her decisions fair? } \\
\text { Do you trust your boss's evaluation of your work? } \\
\text { Do you think that targets given to you are reasonable? } \\
\text { Do you thing that employees are promoted and rewarded fairly? }\end{array}$ \\
\hline Accountability & $\begin{array}{l}\text { Are you made accountable for your behavior and actions? } \\
\text { What kind of consequences do you expect if you do not follow the SOPs? } \\
\text { Are you provided with a chance to explain your behavior in case you violate } \\
\quad \text { any of the SOPs? } \\
\text { Does your boss strive to ensure that employees openly and honestly share } \\
\text { their knowledge and practices with others? } \\
\text { Are you ever stimulated by him to explain to stakeholders why certain } \\
\text { decisions were taken? } \\
\text { Do employees accept responsibility for their actions? } \\
\text { Is accountability same for everyone including senior managers? }\end{array}$ \\
\hline Learning & $\begin{array}{l}\text { Are you motivated for learning new skills? } \\
\text { Do you get any rewards for improving your skills and performance? } \\
\text { Does your leader offer time and support for learning? } \\
\text { Does your leader give rewards for learning? } \\
\text { Does your leader continually look for opportunities to learn new things? } \\
\text { Does your leader invest in professional training and development? }\end{array}$ \\
\hline
\end{tabular}

the collected data. We followed Strauss and Corbin (1990) to avoid the overlapping of data in different categories and did not leave out any data due to unavailability of a suitable category. Then axial coding was used to link major and sub-categories. In the final stage, selective coding was used to integrate the findings with the theory. Themes are presented in table (2).

\section{Empirical Results}

\subsection{Accountability}

In terms of accountability, Alpha Petroleum has in place standard operating procedures (SOPs) ranging from technical standards for managing the receipt, record and delivery of fuel and safety standards to performance and reward management systems.

"There are strict guidelines regarding every operation and procedure in our company. We are bound to follow those. For any deviation, we are penalized" (Fuel storage operator). 
Table 2: Themes Emerged from the Data

\begin{tabular}{|c|c|}
\hline Themes & Supporting evidence \\
\hline Fairness & $\begin{array}{l}\text { "Its not ideal. Political affiliations affect their decisions in many cases" (Filling } \\
\text { operator). } \\
\text { "Yes, there are issues as far as fairness is concerned. I feel people are not treated } \\
\text { equally. And you know promotions are clearly political" (Quality Assistant). } \\
\text { "When employees they are performing well and they expect promotions. But it } \\
\text { is not in our hands. We are usually given lists from the minister [the company } \\
\text { is headed by the minister of petroleum] to promote employees. We have to } \\
\text { follow it" (Divisional Manager South) } \\
\text { "If someone has political links, it is easy for them to get promotion. There are } \\
\text { performance standards but it usually doesn't means that you are getting promo- } \\
\text { tion" (Sr. Logistics Officer). } \\
\text { "It is happening in the entire country. So no exception for us at all. You need } \\
\text { to focus on developing political links to get promotions" (Field Sales Represen- } \\
\text { tative) }\end{array}$ \\
\hline Accountability & $\begin{array}{l}\text { "Its same for everyone when it comes to punishment if we make any mistake in } \\
\text { technical matters. But no one is bothered when it comes to general perfor- } \\
\text { mance standards violations. So we focus on meeting all the technical SOPs. } \\
\text { That's the whole thing" (Quality Assurance Engineer). } \\
\text { "Managers are safe. But usually we are not spared for any technical violation. } \\
\text { Everything else does not matter" (Supervisor Mechanical) } \\
\text { "They operate equipment and machinery They need to be expert. They are the } \\
\text { ultimate in charge of the equipment and any machinery. So they should be } \\
\text { accountable" (Director Quality Assurance). } \\
\text { "If any staff member who violates SOPs, they are warned in case of a minor } \\
\text { mistake. If it's a big fault, their annual [salary] raise may be stopped or they get } \\
\text { demotions. In case of any theft or mixing in oil, they may get their contracts } \\
\text { terminated (Head of Logistics). } \\
\text { "Everyone is accountable. But I am not sure about the top management. They } \\
\text { have plenty of ways to hide their mistakes. They usually put the burden of their } \\
\text { errors and omissions on us" (Lubricant In-charge) }\end{array}$ \\
\hline $\begin{array}{l}\text { Constructive } \\
\text { learning }\end{array}$ & $\begin{array}{l}\text { "As I told you, you won't get reward for extra efforts. So I focus on doing what } \\
\text { can help me avoid any mistake in using equipment and other technical tasks" } \\
\text { (Fuel Depot Operator). } \\
\text { "Why would you learn something new when you don't get any benefit in re- } \\
\text { turn? Yes, I am expert in my work. I am just too good, I believe. Never got any } \\
\text { warning" (Quality Control Engineer Mechanical). } \\
\text { "We have trained them for the specialized jobs. Mostly they are very good. We } \\
\text { usually don't get complaints" (Technical Director). }\end{array}$ \\
\hline $\begin{array}{l}\text { Destructive } \\
\text { learning }\end{array}$ & $\begin{array}{c}\text { "Promotions are biased. Then I have to work on making relations with some } \\
\text { senior politician" (Assistant Manager Retail). } \\
\text { "We know many decisions are political. But everyone knows how it works here. } \\
\text { It's the part of work environment here. We have our own limitations" (Human } \\
\text { Resource Director). } \\
\text { "You know there is no theft. No complaints of quality. Its working. We have } \\
\text { overcome these malpractices" (Senior Manager North). } \\
\text { "Things as far as technical matters are concerned are in control. But we can't } \\
\text { claim that this } 100 \% \text { " (Senior Human Resource Manager) }\end{array}$ \\
\hline
\end{tabular}


"We know what SOPs we have to follow for the routine operations. For instance, what type of lorry you have to use to carry fuel is clearly mentioned. Similarly, our operations manual clearly describes the temperature at which fuel should be stored. We can't avoid following the SOPs. Otherwise, management would not spare you for any incident that happened because of your negligence" (Reservoir Controller).

Alpha has a very strict system to check the quality of oil products.

"We have our own laboratory in our depot. Laboratory checks the quality of petrol before filling it in oil tankers. Surprise visits from quality audit department also ensures that the quality of oil product is up to the standards" (Technical Director).

Alpha has established a department under the direct supervision of managing director (MD). The department uses mobile testing units to check the fuel quality in any depot located anywhere in the country. In case of any violation from quality standards, the department takes serious actions to hold accountable the employees involved in any kind of adulteration in the oil product.

Following the SOPs is particularly important for companies dealing with petroleum products, as petroleum products carry high risk. A small negligence can have detrimental consequences for the company and its customers.

"You know there is always high risk. A small negligence can cause ignition and fire. So no one is spared for violating the standards. Depending on the loss that incurred or would have incurred, punishment can range from a written warning to demotions to employment contract termination" (General Manager Retail).

Accountability has contributed to impede the penetration of destructive practices such as corruption in financial matters, fuel stealing and the illegal mixing of impurities in the fuel.

"We usually don't get complaints about quality. Everyone is clear about what they are bound to do and what can happen with their careers if they show some negligence or sluggishness. There were cases of mixing of impurities in fuel and fuel steeling. But since the adoption of mobile testing units particularly and zero tolerance for such things, we have given a clear message to everyone and overcame such issues" (Managing Director).

Importantly, accountability enhances employees' learning, as it is essential for the employees to fully understand the SOPs and learn how to achieve the required standards.

"Yes, we have to master the SOPs. We can't survive in here otherwise. You can 
get a chance sometime if you are lucky enough, but you can't last long" (Process Control Engineer).

This suggests that accountability enhance learning; however, it can be seen from the data presented so far that the focus of the company as well as employees is on learning how to meet minimum standards.

\subsection{Fairness}

In terms fairness, Alpha employees were only partly satisfied. They were satisfied with the way employees are warned and punished for violating any of the SOPs.

"People are fairly treated as far as they fault with SOPs and for anything substandard they do. It is equal for everyone. This is what makes me stay in the company" (Engineer Quality Control).

The key problem relating to fairness is the unfair reward and promotion system. The interviewees including managers who are responsible for promoting and rewarding employees showed dissatisfaction with the reward and promotion system. Most of the employees had to wait many years to get promotion. This is happening due to at least two reasons. First, it is due to the promotion system that allows only a small percentage of employees to get promotion despite their good performance and hard work. This system based on a bell curve is explained by one of the divisional manager in South Zone as follow:

"We have to follow bell curve strategy for promotion. We are restricted to promote only 4 out of 25 employees. It is very hard job for me. When the expectations of people are too high and they are performing well. I always tried my level best to promote the employees who well deserve. But I am bound to recommend only 4 out of 25 ”.

Secondly, the most common opinion in Alpha is that employees with strong political links with the politicians / ministers of the ruling party get promotion.

"Yes, it's true. Many of them get promotions because of their strong political affiliations. You know it's a semi-government organization. We have to do it or else we face the consequences in terms of transfers in far from places. We also fear lack of promotion opportunities" (Human Resources Development Manager).

"In last 10 years, I never get promoted and my colleagues with political links get promotion in every one or two year. I am here because at least all of us get annual fixed salary raise. It's also a permanent government sector job” (Assistant Manager Sales).

The lack of fairness is affecting Alpha in at least two ways. First, employees are 
only interested in learning things that are helpful for their survival in Alpha. That is, they are inclined to learn skills that help them meet minimum performance standards to avoid mistakes in everyday practices. Second, they do not focus on learning new practices. Rather, they spend time and resources to develop political affiliations to get promotions.

"I know hard work does not matter here. So my aim is to do technical things including reporting efficiently. I am not bothered about extra effort, learn something new or even think out of the box. It doesn't pay. Do the routines in the best possible way. That's it" (Installation Assistant).

"You know they promote you usually on the basis of political references. Ruling party oblige their relations and voters this way. I focus on not doing anything wrong in my normal tasks. I know I will get through to the next level if I am able to have some strong political reference" (Deputy Manager Central Zone).

This suggests that if leaders are unfair in their actions, it is difficult to motivate employees to learn new practices. Thus, unfair leaders hamper organizational learning. The key findings are summarized in the following figure (1).

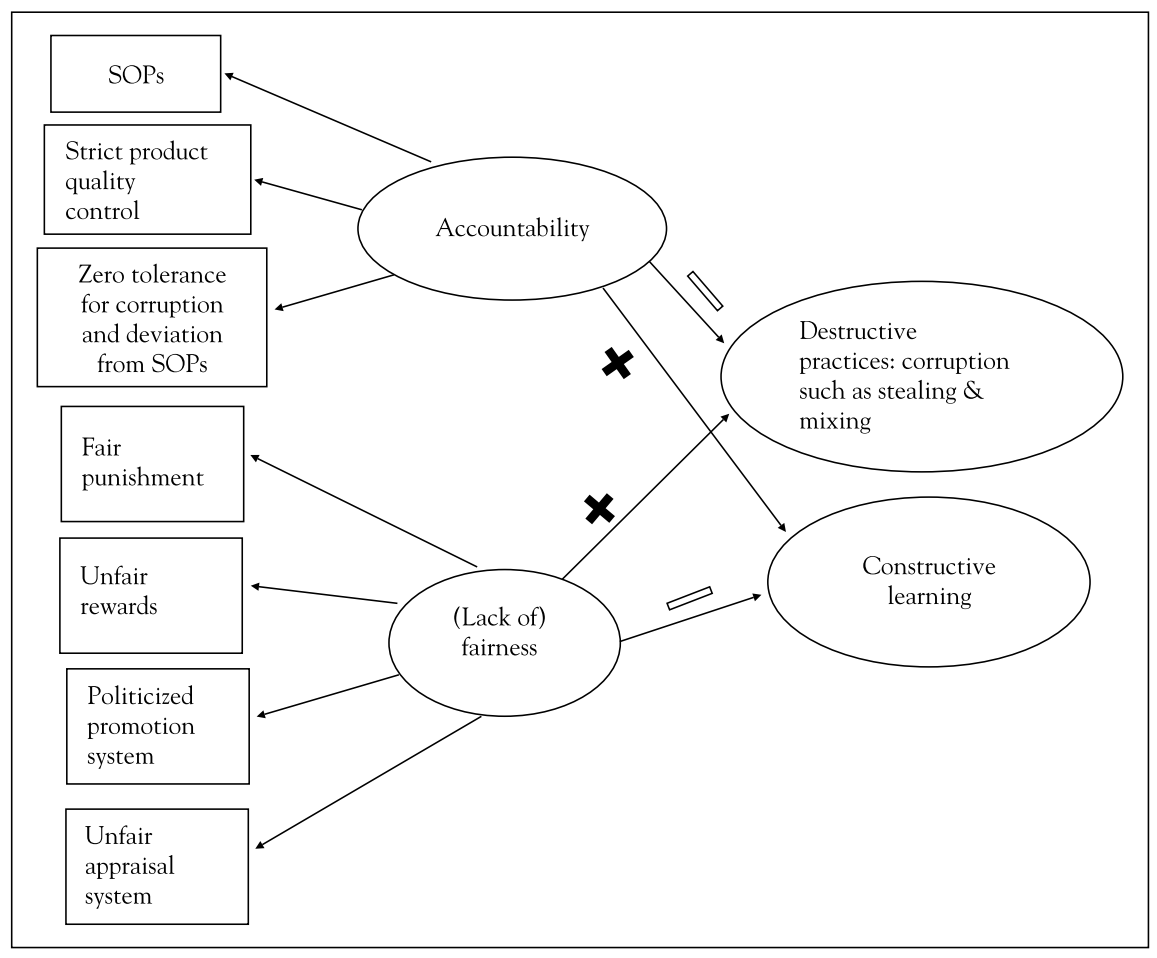

Figure 1: Ethical leadership and learning framework 
The figure (1) depicts the links between ethical leadership - accountability and fairness - organizational learning and destructive practices. Leadership in Alpha Petroleum has developed strict accountability system that includes SOPs, strict fuel quality test system and zero tolerance for corruption and other destructive practices. The presence of accountability discourages (figure 1, negative sign) the penetration of destructive practices such stealing, mixing in fuel and the misuse of organizational resources. Moreover, accountability enhances (shown in figure 1 using positive sign) constructive learning. However, Alpha Petroleum leadership lacks fairness. Promotions are usually based on political affiliations. Performance appraisal and reward systems are unfair. This has enhanced (figure 1, positive sign) the penetration of destructive practices in Alpha Petroleum. The lack of fairness has also discouraged constructive learning (figure 1, negative sign). For instance, employees spent more time in developing political relations instead of improving their skills, as they perceive that improvement in skills and performance is not fairly evaluated and rewarded.

\section{Discussion}

Ethical leaders demonstrate accountability, fairness, honesty and concerned for others and set standards for their followers (Brown \& Treviño, 2006; Brown et al., 2005; Kalshoven et al., 2011; Xu et al., 2016). In this study, we focused on accountability and fairness as the aspects of ethical leadership and the links of these constructs with organizational learning. Our findings suggest that accountability and fairness are the important aspects of ethical leadership in terms of their effects on learning.

Our findings suggest that the presence of a strict accountability mechanism for employees encourages rather forces them to fully understand the SOPs and enhances their knowledge necessary to meet the required standards of performance. Importantly, our findings reveal that accountability prevents the penetration and propagation of destructive practices such as oil thefts, the mixing of cheap solvents in the petroleum products and other such harmful practices in the organization. This accords with Brown et al. (2005), who suggest that ethical leaders develop mechanisms that discourage the propagation of unethical practices in organizations.

The lack of fairness and accountability for leaders confines employees' learning to the minimum performance standards. These absences discourage employees from learning new practices or discovering novel ways of performing routine tasks. Employees focus on gaining expertise that helps them avoid any warnings or punishments instead of gaining new knowledge and learning new skills. The data suggests that, as far as accountability in Alpha is concerned, only employees are made accountable for failing to perform as per set standards. Moreover, the accountability scope is limited to explicit technical matters such as following standards for fuel handling and refueling 
practices, the use of equipment and other technical operational matters. The focus of the management is on the smooth functioning of the equipment and machinery along with maintaining the quality of oil products. The leadership is more concerned about their own promotions and comfort and in the process sacrifices rewards for others' merit. Accountability in Alpha Petroleum at the level of the leaders seems flawed if not absent. They did not seem to fear accountability while promoting employees on the basis of political affiliations instead of performance. This has limited the scope of employee learning. This finding concurs with Snell (2001), who proposes that the absence of moral and ethical values amongst leaders hampers individual and organizational learning.

Importantly, our study shows that the lack of fairness and the absence of accountability for leaders contribute to the development of a culture in the organization that supports employees learning unethical / unfair practices such as the use of political links for promotion. Our data suggests that the leadership of the company does not seem to be fair. Interviewees were dissatisfied particularly with the promotion system. Employees' promotions are based on political links instead of performance. Thus, employees focus on developing political links instead of enhancing their learning beyond a certain minimum level.

\section{Conclusion}

This study investigated the effect of two aspects of ethical leadership - accountability and fairness - on organizational learning. A single case of Alpha Petroleum was used as a research methodology and data was collecting through 35 semi-structured interviews from employees and managers.

This study shows that accountability contributes to constructive organizational learning. However, what employees learn may depend on how fairness and accountability are practiced and followed by the leaders. In other words, if leadership does not follow the accountability and fairness aspects of ethical leadership, organizations may learn destructive practices. If leaders force ethical behaviors on their followers through normative controls and do not follow the fairness and accountability aspects of ethical leadership, destructive practices' penetration in the organization can be deterred. However, in such a case, constructive learning can be restricted to the level that is only adequate to meet the minimum performance standards. Moreover, accountability also discourages employees from learning bad practices such oil theft and mixing impurities in the fuel, and thus, deters the penetration of bad practices in the organization.

Our findings show that the unfair behavior of leaders creates dissatisfaction 
amongst employees and deters their learning beyond certain minimum standards. The lack of fairness also contributes to the development of an organizational culture that nurtures destructive practices such as employees' interest in improving their political links instead of enhancing their skills.

\subsection{Theoretical contributions}

Our study is important because of its theoretical contributions and practical implications. Our study contributes to the ethical leadership literature (Engelbrecht et al., 2017; Eisenbeiß \& Brodbeck, 2014; Kacmar et al., 2016; Piccolo et al., 2010) and organizational learning literature (Chiva \& Habib, 2015; Mason \& Leek, 2008) by providing empirical evidence of the links between ethical leadership and organizational learning. Importantly, our study foregrounds the ways accountability and fairness aspects of ethical leadership can affect learning.

\subsection{Practical implications}

Organizational leadership must follow fairness and accountability in order to enhance constructive organizational learning. As our findings show, the lack of fairness in Alpha is encouraging employees to develop political affiliations to get promotions. This is resulting in the penetration of bad practices in the organization. The lack of fairness is impeding the unlearning of bad practices. We suggest that by being fair, organizational leadership can halt the penetration of such bad practices in organizations. Organizational leadership can overcome bad learning practices such as corruption in financial matters, stealing of fuel and illegal mixing of impurities in the fuel through implementing accountability. Importantly, by implementing accountability at all levels of the organization, organizational leaders can encourage employees to put extra efforts into learning new practices.

\subsection{Limitations and future research}

This study is not without limitations. This study used a single organization as case study and can be argued to lack generalizability. Thus, future research can use multiple organizations as the case studies (Yin, 1994). This, this research focused on two aspects, accountability and fairness, of ethical leadership in relation to organizational learning. Future research can study these links by focusing on other aspects of ethical leadership such as integrity, honesty, sincerity; authenticity and self-discipline.

Furthermore, Alpha Petroleum operates in oil industry. As learning may vary across contexts (Mason \& Leek, 2008), future studies can focus on companies operating in different other industries can offer valuable insights into the links between ethical leadership and organizational learning. 


\section{References}

Argyris, C., \& Schön, D. (1996). Organizational learning. Reading, MA: Addison-Wesley.

Aguilera, R., \& Vadera, A. (2008). The dark side of authority: Antecedents, mechanisms, and outcomes of organizational corruption. Journal of Business Ethics, 77(4), 431-449.

Arnold, K. A., Turner, N., Barling, J., Kelloway, E. K., \& McKee, M. C. (2007). Transformational leadership and employee wellbeing: The mediating role meaningful work. Journal of Occupational Health Psychology, 12(3), 193-203.

Avolio, B. J., \& Gardner, W. L. (2005). Authentic leadership development: Getting to the root of positive forms of leadership. The Leadership Quarterly, 16(3), 315-338.

Bakari, H., \& Hunjra, A. I. (2017). Authentic leadership questionnaire: Case of its validation through structural equation modelling: Evidence from Pakistan. Business $\mathcal{E}$ Economic Review, 9(2), 21-48

Bandura, A. (1977). Social learning theory. Englewood Cliffs, NJ: Prentice Hall.

Bandura, A. (1986), Social foundations of thought and action: A social cognitive theory, Englewood Cliffs, N J: Prentice Hall.

Bozionelos, N., \& Wang, L. (2007). An investigation on the attitudes of Chinese workers towards individually based performance-related reward systems. The International Journal of Human Resource Management, 18(2), 284-302.

Brown, M. E., \& Treviño, L. K. (2006). Ethical leadership: A review and future directions. The leadership quarterly, 17(6), 595-616.

Brown, M. E., Treviño, L. K., \& Harrison, D. A. (2005). Ethical leadership: A social learning perspective for construct development and testing. Organizational Behavior and Human Decision Processes, 97(2), 117-134.

Bryman, A., \& Bell, E (2007). Business research methods, Oxford: Oxford University Press.

Burns, J. M. (1978). Leadership. New York: Harper Row.

Chiva, R., \& Habib, J. (2015). A framework for organizational learning: zero, adaptive and generative learning. Journal of Management $\mathcal{E}$ Organization, 21(3), 350-368.

Coopey, J., \& Burgoyne, J. (2000). Politics and organizational learning. Journal of Management Studies, 37(6), 869-886.

Creswell, J. W. (2003). Research design: Qualitative, quantitative, and mixed methods approaches. Thousand Oaks, CA: Sage.

Dubois, A., and Gadde. L.E. (2002). Systematic combining: An abductive approach to case research. Journal of Business Research, 55(7), 553-560. 
Eisenbeiß, S. A., \& Brodbeck, F. (2014). Ethical and unethical leadership: A cross-cultural and cross-sectoral analysis. Journal of Business Ethics, 122(2), 343-359.

Eisenhardt, K. M. (1989). Building theories from case study research. Academy of Management Review, 14(4), 532-550.

Engelbrecht, A. S., Heine, G., \& Mahembe, B. (2017). Integrity, ethical leadership, trust and work engagement. Leadership $\mathcal{E}$ Organization Development Journal, 38(3), 368-379.

Fiol, C. M., \& Lyles, M.A. (1985). Organizational learning. Academy of Management Review, 10(4), 803-813.

Graneheim, U. H., \& Lundman, B. (2004). Qualitative content analysis in nursing research: concepts, procedures and measures to achieve trustworthiness. Nurse Education today, 24(2), 105-112.

Hassan, S., Wright, B.E., \& Yukl, G. (2014). Does ethical leadership matter in government? Effects on organizational commitment, absenteeism, and willingness to report ethical problems. Public Administration Review, 74(3), 333-343.

Jackson, T. (2001). Cultural values and management ethics: A 10-nation study. Human Relations, 54(10), $1267-1302$.

Kacmar, K. M., Tillman, C. J., Harris, K. J., Whitman, M. V., \& Justice, C. (2016). Perceptions of ethical leadership as a mediator of the relationship between abusive supervision and work behaviors. Journal of Behavioral and Applied Management, 16(1), 2-19.

Kvale, S. (2007). Doing interviews. Thousand Oaks, CA: Sage

Kalshoven, K., Den Hartog, D. N., \& De Hoogh, A. H. (2011). Ethical leadership at work questionnaire (ELW): Development and validation of a multidimensional measure. The Leadership Quarterly, 22(1), 51-69.

Kjellberg, H., \& Helgesson, C. (2006). Multiple versions of markets: Multiplicity and performativity in market practice. Industrial Marketing Management, 35(7), 839-855.

Knights, D., \& O'Leary, M. (2005). Reflecting on corporate scandals: The failure of ethical leadership. Business Ethics: A European Review, 14(4), 359-366.

Law, J. (1994). Organizing modernity. Oxford: Blackwell.

Law, J., \& Urry, J. (2004). Enacting the social. Economy and Society, 33(3), 390-410.

Liu, J., Kwan, H. K., Fu, P. P., \& Mao, Y. (2013). Ethical leadership and job performance in China: The roles of workplace friendships and traditionality. Journal of Occupational and Organizational Psychology, 86(4), 564-584.

Mason, K. J, Oshri, I., \& Leek, S. (2012). Shared learning in supply networks: evidence from an emerging market supply network. European Journal of Marketing, 46(11/12), 743-1762.

Mason, K. J., \& Leek, S. (2008). Learning to build a supply network: an exploration of dynamic business 
models. Journal of Management Studies, 45(4), 774-799.

Mayer, D. M., Kuenzi, M., Greenbaum, R., Bardes, M., \& Salvador, R. B. (2009). How low does ethical leadership flow? Test of a trickle-down model. Organizational Behavior and Human Decision Processes, 108(1), 1-13.

Morgan, G., \& Smircich, L. (1980). The case for qualitative research. Academy of Management Review, 5(4), 491-500.

Ofori, G. (2009). Ethical leadership: Examining the relationships with full range leadership model, employee outcomes, and organizational culture. Journal of Business Ethics, 90(4), 533-547.

Piccolo, R. F., Greenbaum, R., Hartog, D. N. D., \& Folger, R. (2010). The relationship between ethical leadership and core job characteristics. Journal of Organizational Behavior, 31(3), 259-278.

Price, T. L. (2000). Explaining ethical failures of leadership. Leadership $\mathcal{G}$ Organization Development Journal, 21(4), 77-184.

Resick, C. J., Hanges, P.J., Dickson, M. W., \& Mitchelson, J. K. (2006). A cross-cultural examination of the endorsement of ethical leadership. Journal of Business Ethics, 63(4), 345-359.

Resick, C. J., Martin, G. S., Keating, M. A., Dickson, M. W., Kwan, H. K., \& Peng, C. (2011). What ethical leadership means to me: Asian, American, and European perspectives. Journal of Business Ethics, 101(3), 435-457.

Riege, A. (2005). Three-dozen knowledge-sharing barriers managers must consider. Journal of Knowledge Management, 9(3), 18-35.

Rodriguez, P., Siegel, D. S., Hillman, A., \& Eden, L. (2006). Three lenses on the multinational enterprise: politics, corruption, and corporate social responsibility. Journal of International Business Studies, 37(6), 733-746.

Senge, P. (1990). The fifth discipline: The art and science of the learning organization. New York: Currency Doubleday.

Strauss, A., \& Corbin, J. (1990). Basics of qualitative research. Newbury Park, CA: Sage.

Tseng, L-M., \& Wu, J-Y. (2017). How can financial organizations improve employee loyalty? The effects of ethical leadership, psychological contract fulfillment and organizational identification. Leadership Eु Organization Development Journal, 38(5), 679-698.

Treviño, L. K., Weaver, G. R., \& Reynolds, S. J. (2006). Behavioral ethics in organizations: A review. Journal of Management, 32(6), 951-990.

Tuckey, M. R., Bakker, A. B., \& Dollard, M. F. (2012). Empowering leaders optimize working conditions for engagement: A multilevel study. Journal of Occupational Health Psychology, 17(1), 15-27.

Turner, D. W. (2010). Qualitative interview design: a practical guide for novice investigators. The Qual- 
The Effect of Ethical Leadership on Organizational Learning: Evidence from a Petroleum Company 21

itative Report, 15(3), 754-760

Xu, A. J., Loi, R., \& Ngo, H-Y. (2016). Ethical leadership behavior and employee justice Perceptions: The mediating role of trust in organization. Journal of Business Ethics, 134(3), 493-504.

Yin, R. (1994). Case study research: Design and methods. Thousand Oaks, CA: Sage.

Yukl, G., Mahsud, R., Hassan, S., \& Prussia, G. E. (2013). An improved measure of ethical leadership. Journal of Leadership $\mathcal{E}$ Organizational Studies. 20(1), 38-48.

Walumbwa, F. O., Avolio, B. J., Gardner, W. L., Wernsing, T., \& Peterson, S. J. (2008). Authentic leadership: Development and validation of a theory-based measure. Journal of Management, 34(1), 89-126. 
